\title{
A ARTICULAÇÃO DA FORMAÇÃO DE PROFESSORES ÀS NECESSIDADES DE ATUAÇÃO PROFISSIONAL DA EDUCAÇÃO BÁSICA
}

\author{
Suzanna Neves Ferreira ${ }^{1}$, Andréia Nunes Militão ${ }^{2}$ \\ ${ }^{1}$ Graduada em Pedagogia pela Universidade Federal de Goiás (Regional Jataí). Atualmente é mestranda do Programa de Pós-graduação em \\ Educação da Universidade Estadual de Mato Grosso do Sul - UEMS/Paranaíba. Bolsista do Programa Institucional de Bolsas aos Alunos de Pós- \\ Graduação da Universidade Estadual de Mato Grosso do Sul (PIBAP/UEMS), Paranaíba-MS. E-mail: suzanna.pedagogia@gmail.com \\ ${ }^{2}$ Doutora em Educação pela Universidade Estadual Paulista (UNESP), campus de Presidente Prudente. Professora do Programa de Pós-Graduação \\ em Educação da Universidade Estadual de Mato Grosso do Sul - UEMS/Paranaíba, MS.
}

\section{RESUMO}

O presente trabalho integra a pesquisa de mestrado em desenvolvimento junto ao Programa de PósGraduação em Educação da Universidade Estadual de Mato Grosso do Sul. O delineamento do trabalho aqui apresentado parte da seguinte questão: A formação docente está articulada às necessidades de atuação profissional da Educação Básica, particularmente à Educação Infantil e anos iniciais do Ensino Fundamental? Ancorada em abordagem qualitativa, recorre à pesquisa bibliográfica e documental, analisando autores da área e o Projeto Pedagógico do Curso de Licenciatura em Pedagogia da Universidade Federal de Goiás-Regional Jataí. A análise inicial da grade curricular demonstra que a formação de professores da licenciatura selecionada prioriza os conteúdos voltados para os anos iniciais do Ensino Fundamental em detrimento dos demais níveis/modalidades de ensino.

Palavras-chaves: Formação Inicial; Licenciatura em Pedagogia; Projeto Pedagógico do Curso; Educação Básica.

\section{THE ARTICULATION OF TEACHER TRAINING TO THE NEEDS OF PROFESSIONAL ACTIVITY OF BASIC EDUCATION}

\section{ABSTRAC}

The present work integrates the research of masters in development with the Education Postgraduate Program in Universidade Estadual de Mato Grosso do Sul. The outline of the work presented here comes from the following question: Is the teacher education articulated with the Professional performance needs of Basic Education, specially Early Childhood Education and Initial Years of Elementary School Education? Anchored in a qualitative approach, it uses bibliographical and documentary research, analyzing authors of the subject and the Pedagogical Project of the Pedagogy Graduation Course of Universidade Federal de Goiás-Jataí. The initial curriculum analysis shows that the teacher training of the selected course prioritizes the content directed to the Initial Years of Elementary School Education in detriment of the other levels/modalities of teaching.

Keywords: Initial Formation; Degree in pedagogy; Pedagogical Course Design; Basic Education.

\section{INTRODUÇÃO}

No campo da formação de professores, a emergência de estudos sobre as práticas pedagógicas situa-se na década de 1990. Para Diniz-Pereira (2013, p.148) esse cenário favorece a construção de certo "[...] consenso sobre a valorização da prática cotidiana como lugar de construção de saberes. Os saberes escolares e os saberes docentes passaram, então, a se constituir em relevante objeto de pesquisa no Brasil".

Essa reconfiguração, no entanto, não foi incorporada nos processos de elaboração dos Projetos Pedagógicos das Licenciaturas que, a nosso ver, permanecem distantes da realidade da educação básica, não atendendo as necessidades de atuação profissional. 
A pesquisa aqui proposta assume a concepção de currículo como uma construção social, histórica e cultural. Entende, portanto, que o currículo é disputado por distintas perspectivas, levando a propostas diferentes de formação docente. Tais perspectivas ideológicas possuem um marco político que pode ser percebido quando se analisa e se discute sobre o currículo em ação. De acordo com Moreira e Candau (2006), à palavra currículo associam-se distintas concepções, que derivam dos diversos modos de como a educação é concebida historicamente, bem como das influências teóricas que a afetam e se fazem hegemônicas em um dado momento. Neste sentido,

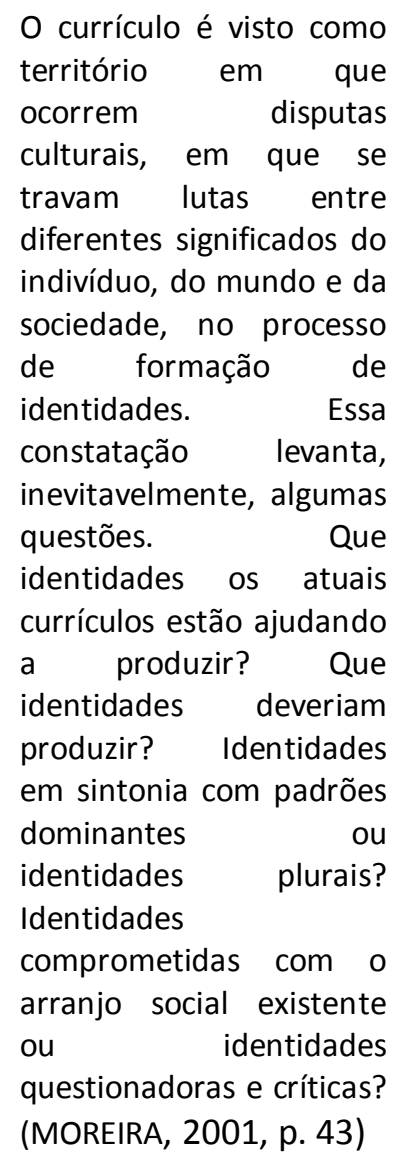

Nessa perspectiva, a universidade tem seu papel social definido historicamente, imbuído da responsabilidade de formar profissionais que atuem na sociedade e contribuam para a sua construção. E é por meio dos currículos que é possível compreender as concepções de sociedade, de homem e de mundo que se quer construir.

Corroborando com esta ideia, Limonta (2009) ressalta que o ensino superior é entendido também como peça-chave na tarefa de qualificar os trabalhadores para a modernização da sociedade brasileira. Além disso, "é considerado fator relevante na melhoria da qualidade da Educação Básica, uma vez que forma, em quase sua totalidade, os professores da Educação Infantil, Ensino Fundamental e Ensino Médio" (LIMONTA, 2009, p. 30).

Para Diniz-Pereira (2013), o campo de pesquisa sobre formação de professores representa um espaço/arena de lutas e interesses onde se estabelecem relações de força e poder. Assim, as discussões sobre currículo devem incluir reflexões sobre o professorado e sua formação. Nesse sentido, esta pesquisa propõe-se a investigar a articulação entre a formação inicial de professores de Pedagogia às necessidades de atuação profissional a partir da análise do Projeto Pedagógico da Licenciatura em Pedagogia da Universidade Federal de Goiás Regional Jataí.

\section{METODOLOGIA}

A pesquisa aqui empreendida é de cunho qualitativo e elege como procedimentos a análise bibliográfica e documental. Para atender ao seu propósito - investigar a articulação entre a formação inicial de professores de Pedagogia e as necessidades de atuação profissional - este trabalho ancora-se nos pressupostos da abordagem qualitativa e tem como objetivo interpretar os desafios presentes na formação inicial docente, levando-se em conta as especificidades contidas no Projeto Pedagógico da Licenciatura em Pedagogia da Universidade Federal de Goiás.

Severino (2007) afirma que o conhecimento não pode ser entendido isoladamente em relação à prática. Assim, a pesquisa qualitativa nos dá a oportunidade de ter uma visão mais direta do objeto estudado, fazendo-se análise dos elementos que o constituem, na tentativa de compreender esse objeto, suas implicações no contexto social, a partir do que se pode propor mudanças. Nesse sentido, o autor aponta que a práxis humana é fundamental, pois a ação guiada por uma intencionalidade lhe dá um sentido, uma finalidade intensamente relacionada com a transformação.

De acordo com Severino (2007, p.122), "a pesquisa bibliográfica é aquela que se realiza a partir do registro disponível, decorrente de pesquisa anteriores, em 
documentos impressos, como livros, artigos, teses, etc.". Lakatos e Marconi (2010) esclarecem que "[...] a pesquisa bibliográfica não é mera repetição do que já foi dito ou escrito sobre certo assunto, mas propicia o exame de um tema sob novo enfoque ou abordagem, chegando a conclusões inovadoras" (2010, p. 166). Desta forma, para compreender os principais limites e possibilidades da proposta curricular do curso de Pedagogia é necessário conhecer a produção da área.

Visando compreender se há articulação entre a proposta de formação inicial de professores de Pedagogia e a Educação Básica, recorremos também à pesquisa documental. Para tanto, foram consultados documentos oficiais, ou seja, aqueles produzidos no âmbito da instituição pesquisada e normativos nacionais. O corpus documental reúne leis, pareceres, resoluções e o projeto pedagógico do curso examinado.

\section{DISCUSSÃO}

A educação básica no Brasil é garantida como direito do cidadão e dever do Estado, assegurada no texto da Constituição Federal (1988) e presente na Lei de Diretrizes e Bases da Educação Nacional (Lei no 9.394/96). Cury (2010, p. 2) aponta que "como direito, significa um recorte universal próprio de uma cidadania ampliada, ansiosa pelo encontro com uma democracia civil, social, política, cultural e com os direitos humanos", para este autor á educação é um pilar da cidadania, pois a educação básica é constituída por três etapas, sendo elas: a educação infantil, o ensino fundamental e o ensino médio, o autor utiliza a metáfora que "a educação infantil, raiz do processo, o ensino fundamental, seu tronco e o ensino médio, seu acabamento".

Assim, o autor considera que a "[...] educação básica é um direito e intenciona o aprendizado de saberes válidos para toda e qualquer pessoa e responde a necessidades educativas do desenvolvimento humano como patrimônio cultural" (CURY, 2010, p.3). Desta forma, cabem às instituições escolares descontruir estereótipos, por meio do seu papel socializador de conhecimentos científicos e propiciar aprendizagens significativas.

Compreendemos que "à educação básica do presente século está reservado papel significativo no processo de socialização e formação de homens e mulheres, diante das mudanças contemporâneas [...]" (BRZEZINSKI, 2007 , p. 231). A autora aponta que as rápidas mudanças que ocorrem na sociedade, ocasionadas pela revolução tecnológica, impõem também desafios à formação de professores, pois estes devem ser capazes de promover uma educação escolar e não-escolar com qualidade que atenda a essa nova realidade.

Portanto, Sales (2010, p. 2) destaca que objetivo das diretrizes curriculares é fornecer subsídios para consolidação de uma educação de qualidade, a todos sem distinção, assim,

As diretrizes insistem que
seu papel é subsidiar a
elaboração das propostas
pedagógicas das
secretarias, do
planejamento curricular
dos sistemas de ensino e
do projeto político
pedagógico de cada
estabelecimento escolar,
conforme preconiza a
legislação. Tais planos e
projetos devem estar em
consonância com a
sociedade local e
regional. As diretrizes têm
por função contemplar
elementos fundamentais
do ensino, garantindo
que cada aluna/o tenha
acesso a uma educação
de qualidade em todo o
país.

Desse modo, as Diretrizes Curriculares Nacionais da Licenciatura em Pedagogia são resultantes de longa tramitação no Conselho Nacional de Educação e se aplicam à formação inicial para o exercício da docência na Educação Infantil, nos anos iniciais do Ensino Fundamental, em cursos de Educação Profissional na área de serviços e apoio escolar bem como em áreas em que seja necessário o conhecimento pedagógico.

A licenciatura em Pedagogia destina-se à formação de professores para exercer funções de docência na Educação Infantil e nos anos iniciais do Ensino Fundamental e, ainda, nas seguintes modalidades: educação de jovens e adultos, educação especial, educação escolar indígena, educação do campo, educação escolar quilombola e educação à distância. Assim, a partir do parecer CNE/CP n. 5/2005, 
homologado em 20 de dezembro de 2005, a licenciatura em Pedagogia passa a ser o principal formador de professores, pois prepara docentes para dois níveis da educação básica.

A Resolução no 2, de 1ㅇ de julho de 2015, que trata da formação inicial do magistério da educação básica em nível superior, em seu artigo 14으, define que,

20 Os cursos de formação deverão garantir nos currículos conteúdos específicos da respectiva área de conhecimento ou interdisciplinares, seus fundamentos e metodologias, bem como conteúdos relacionados aos fundamentos da educação, formação na área de políticas públicas e gestão da educação, seus fundamentos e metodologias, direitos humanos, diversidades étnico-racial, de gênero, sexual, religiosa, de faixa geracional, Língua Brasileira de Sinais (Libras), educação especial e direitos educacionais de adolescentes e jovens em cumprimento de medidas socioeducativas (BRASIL, 2015, p.12).

Importante destacar que a Resolução n. 2, de 10 de julho de 2015 atinente às Diretrizes Curriculares Nacionais para a formação inicial em nível superior caracteriza os profissionais do magistério como "[...] aqueles que exercem atividades de docência e demais atividades pedagógicas, incluindo a gestão educacional dos sistemas de ensino e das unidades escolares de educação básica, nas diversas etapas e modalidades de educação" (BRASIL, 2015, p. 1). Entre estes profissionais, os licenciados em Pedagogia podem atuar nos cargos referentes à gestão da escola e dos sistemas de ensino, mas também nos níveis Educação Infantil (creche e pré-escola) e nos Anos Iniciais do Ensino Fundamental (1음 ao 5o ano) além de poderem atuar nas seguintes modalidades Educação de Jovens e Adultos, Educação Especial, Educação Escolar Indígena, Educação do Campo, Educação Escolar Quilombola e Educação à Distância.
O amplo campo de atuação profissional dos licenciados em Pedagogia indicado no documento supracitado, leva-nos a buscar compreender como universidade articula com os sistemas educacionais a preparação destes futuros profissionais. Questiona-se qual o lugar no currículo da licenciatura em Pedagogia da Universidade Federal de Goiás- Regional Jataí destinados aos níveis e modalidades mencionados?

De acordo com as Diretrizes Curriculares Nacionais da Licenciatura em Pedagogia, o curso terá a carga horária mínima de 3.200 horas, sendo 2.800 horas dedicadas às atividades formativas, 300 horas dedicadas ao Estágio Supervisionado em Educação Infantil e nos anos iniciais do Ensino Fundamental, contemplando também outras áreas específicas, conforme o projeto pedagógico da instituição e 100 horas de atividades teóricopráticas são destinadas à iniciação científica, à extensão e monitoria.

O Art. 80 das Diretrizes Curriculares Nacionais da Licenciatura em Pedagogia determina que a integralização de estudos seja efetivada por meio de disciplinas, seminários e atividades de natureza predominantemente teórica que farão a introdução e o aprofundamento de estudos. A prática será realizada intermédio do estágio curricular a ser realizado ao longo do curso, em espaços escolares e não-escolares. De acordo com esse artigo, o estágio deverá fortalecer as atitudes éticas, os conhecimentos, contemplando as seguintes áreas e competências:

a) Educação Infantil e nos anos iniciais do Ensino Fundamental,

prioritariamente; b) nas disciplinas pedagógicas dos cursos de Ensino Médio, na modalidade Normal; c) na Educação Profissional na área de serviços e de apoio escolar; d) na Educação de Jovens e Adultos; e) na participação em atividades da gestão de processos educativos, no planejamento, implementação, coordenação, acompanhamento e avaliação de atividades e projetos educativos; f) em 
reuniões de formação pedagógica (BRASIL, 2005, p. 9).

Tendo em vista a problemática da dicotomia entre a teoria e a prática, as Diretrizes Curriculares Nacionais da Licenciatura em Pedagogia, prevê a articulação entre esses dois elementos no processo de formação inicial dos professores, contemplando a indissociabilidade entre ensino, pesquisa e extensão e reconhecendo as instituições de educação básica como espaços necessários à formação dos profissionais do magistério. Os cursos a serem criados em instituições de educação superior e os que já estão em funcionamento deverão ser estruturados com base nestas Resoluções.

As Diretrizes Curriculares Nacionais para a formação inicial em nível superior (cursos de licenciatura, cursos de formação pedagógica para graduados e cursos de segunda licenciatura) e para a formação continuada (2015) consideram que a identidade do professor da educação básica, deverá ser garantida, ao longo do processo, efetiva e concomitante à relação entre teoria e prática, ambas fornecendo elementos básicos para o desenvolvimento dos conhecimentos e habilidades imprescindíveis à docência.

Assim, Libâneo (2015) aponta para a necessidade de que os currículos assegurem aos professores em formação, conhecimentos inerentes do campo educacional, como o conhecimento do processo de aprendizagem,

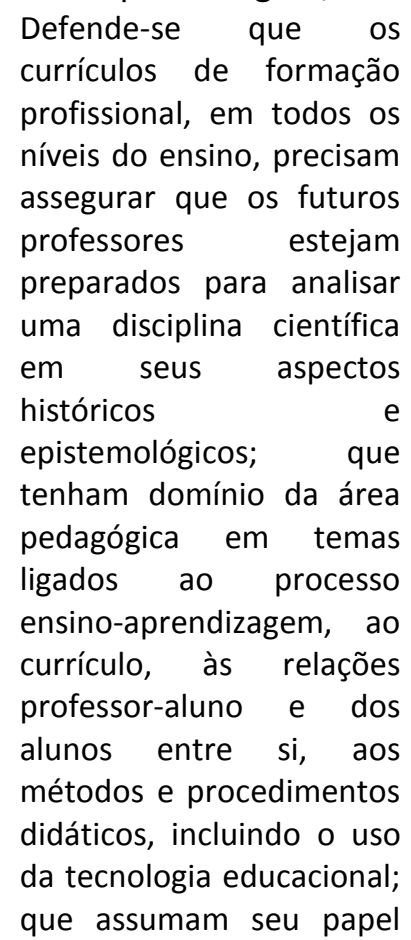

de educadores na
formação ra
personalidade dos alunos
e que incorporem na
prática docente a
dimensão política
enquanto cidadãos e
formadores de cidadãos e
profissionais (LIBÂNEO,
2015, p. 19).

Sabemos da exigência de se formar cada vez mais profissionais para atuarem no mercado de trabalho, mas pouco se reflete sobre a qualidade desta formação. Saviani (2012) afirma que toda prática educativa contém inevitavelmente uma dimensão política, no caso específico da formação docente, cabe indagar se a formação docente está articulada às necessidades de atuação profissional da Educação Básica, particularmente na Educação Infantil e nos anos iniciais do Ensino Fundamental? A legislação indica que cabe ao curso de Pedagogia a formação de professores para Educação Infantil e para os primeiros anos do Ensino Fundamental. Será que o curso atende às expectativas que essa educação exige? Questiona-se, ainda, se há espaço destinado a formação para as modalidades citadas nos normativos legais?

O Projeto Pedagógico do Curso de Pedagogia da Universidade Federal de Goiás (Regional-Jataí), em vigor, foi elaborado em 2003. O referido projeto curricular é resultado de um conjunto de debates e análises realizadas no âmbito da Faculdade de Educação e das regionais de Catalão e Jataí.

O Projeto Político do Curso de Pedagogia apresenta, em sua parte inicial, o histórico e a justificativa do projeto em vigor; na segunda parte, aborda a docência em Educação Infantil e nos anos iniciais do Ensino Fundamental: eixos epistemológicos e objetivos do currículo; na terceira seção é apresentada a estrutura curricular; na sequência apresentam-se as bases da organização curricular, a duração do curso, a carga horária e a integralização curricular e, por fim, previsão de adequação ao novo currículo para o ano letivo de 2004, esta grade curricular é a mesma para os alunos de 2017.

O texto do PPC contém uma análise do cenário econômico, político e social, pois estes impactam diretamente na área da formação de professores e na estruturação dos currículos. 
Destaca, dentre outros aspectos, a reestruturação da esfera produtiva que tem sido colocada como hegemônica nas prioridades, na forma de organização e funcionamento impostos como se fossem os únicos possíveis e admissíveis.

A licenciatura em Pedagogia foi concebida em três núcleos: núcleo comum, núcleo específico e núcleo livre.

Tendo em vista a
formação do pedagogo
para atuar em dois
momentos indissociáveis
do trabalho educativo,
educação infantil e anos
iniciais do ensino
fundamental, as disciplinas
e atividades previstas no
núcleo comum e no
núcleo específico são
obrigatórias. O pedagogo
formado neste curso será
habilitado para atuar,
indistintamente, nos dois
momentos desse processo
da formação humana
(UFG, 2003, p.20).

Denota-se que a ênfase da Licenciatura em Pedagogia da UFG/Regional Jataí centra-se na formação para atuação na Educação Infantil e anos iniciais do Ensino Fundamental, sem mencionar as modalidades. Esse aspecto precisa ser melhor equacionado, pois as Diretrizes Curriculares da Educação Básica (2013) indicam para os sistemas de ensino (municipal, estadual e federal):

[...] que crianças,
adolescentes, jovens e
adultos que ainda não
tiveram a oportunidade,
possam se desenvolver
plenamente, recebendo
uma formação de
qualidade correspondente

à sua idade e nível de aprendizagem,

respeitando

suas

diferentes

condições

sociais, culturais, emocionais, físicas e étnicas (BRASIL, 2013, p. 6).

Assim, o PPC reforça a concepção de que a licenciatura em Pedagogia forma apenas para a Educação Infantil e Anos Inicias do Ensino Fundamental. De outro lado, os normativos legais indicam que a formação inicial também aborde as modalidades de modo que propicie vivências com a educação do campo, com a educação indígena, quilombola e educação especial.

Não são apenas os normativos legais que preveem que o professor no seu processo de formação inicial tenha contato e conhecimento epistemológico para além da educação infantil e anos iniciais, a prática docente exige do professor conhecimentos que na maior parte não são proporcionados no processo de formação inicial e, desta forma, temos professores que não estão preparados para lidar com alunos com deficiência, estes alunos ficam na responsabilidade do professor de apoio, geralmente estudantes em situação de estágio.

Vemos que às 3.200 horas previstas pela resolução CNE/CP no 2/2015 para a conclusão da licenciatura em Pedagogia não é suficiente para todas as funções, são impossíveis de ser concretizadas na formação inicial.

De acordo com o PPC, o curso de Pedagogia da Universidade Federal de GoiásRegional de Jataí terá a duração de 3.120 horas a serem cumpridas em oito semestres, sendo a carga horária total dividida, conforme o quadro abaixo:

Quadro 01. Núcleos Disciplinares

\begin{tabular}{|c|l|}
\hline Horas & \multicolumn{1}{|c|}{ Integralização curricular } \\
\hline 1.512 & Disciplinas do núcleo comum \\
\hline 832 & Disciplinas do núcleo específico \\
\hline 576 & Núcleo livre \\
\hline 200 & Atividades complementares/ atividades acadêmico-científico-culturais \\
\hline
\end{tabular}

Fonte: Pesquisa realizada, 2017. 
O Núcleo Livre compreende o conjunto de disciplinas de escolha direta pelo aluno, distribuído em cada semestre letivo, com exceção do primeiro. Este núcleo é caracterizado pela flexibilização curricular, perfazendo um total de 576 horas $(19,7 \%$ da carga horária total do curso). De acordo com as ofertas registradas no cadastro do Sistema Integrado de Gestão de Atividades Acadêmicas (SIGAA), os alunos se matriculam nas disciplinas escolhidas conforme a sua média global, ou seja, tem prioridade aquele que alcança maior média. Um modelo excludente de seleção, visto que todos os alunos deveriam escolher livremente tais disciplinas para integralização do currículo, mas o que ocorre é a pouca oferta de disciplinas no Núcleo Livre que não atende à demanda. Apesar de os Núcleos Livres preverem flexibilização curricular para que os alunos conheçam outras áreas, o resultado assevera-se em alunos insatisfeitos com esse sistema, tendo que cursar a disciplina que dispõe de vaga, apenas visando o cumprimento de horas, disciplinas essas que, muitas vezes, não se vinculam à sua área de formação, preenchendo apenas as horas necessárias para a conclusão do curso. Outro aspecto importante é que os horários do Núcleo Livre não são compatíveis com os alunos que estudam no período noturno e trabalham durante $o$ dia, estando em desacordo com realidade desta comunidade acadêmica.

O Projeto Pedagógico do Curso aponta para a necessidade de se ampliar o currículo para a área da Educação Infantil, porém de 2003 até o ano de 2017 não houve alterações em relação a esta lacuna na formação inicial dos professores. A análise da grade curricular demonstra que a formação de professores da licenciatura selecionada prioriza os conteúdos voltados para os anos iniciais do Ensino Fundamental em detrimento das demais modalidades de ensino que preconizam as Diretrizes Curriculares Nacionais Gerais para Educação Básica (2013).

Não defendemos aqui a ideia de que a universidade deva se adaptar/acompanhar a demanda do mercado/capital. Entendemos que seu currículo deve estar em sintonia com o contexto social, econômico e político, pois nele estão impressas as concepções de sociedade e de profissional que se pretende formar. Se as políticas não são as mesmas de dez anos atrás, estando em constantes alterações, acrescentamos então que essa grade curricular de 2004 não atende às necessidades atuais, no ano de 2017. Verificamos, ainda, lacunas em modalidades/níveis de ensino em que o licenciado em Pedagogia deverá atuar e que exigem dele conhecimentos, competências e habilidades.

Existe a problemática entre a prática e teoria, como há entre os normativos legais e a sua efetivação. Porém, diferentemente da concepção restrita, a licenciatura em Pedagogia não forma ou não deveria formar apenas para Educação Infantil e para os anos iniciais do Ensino Fundamental.

0 pedagogo não é formado exclusivamente para a docência para a educação infantil e anos iniciais do ensino fundamental.

Compreendo que a unidade da formação do pedagogo está perspectivada em diferentes dimensões que possibilitam compreender a complexidade da Educação Básica e da escola, dominar conteúdos básicos da Educação, da Pedagogia e de outros campos de saber, aprofundar estudos diversificados integradores, desenvolver a investigação educacional e conhecer procedimentos de gestão de sistemas e instituições de ensino, englobando planejamento, execução, coordenação, acompanhamento de projetos e experiências educativas em contextos escolares e não-escolares. Como se constata, a formação do pedagogo é abrangente e complexa, assegurá-la exige inegavelmente a ressignificação de muitos conceitos e práticas de formação que ainda repousam na racionalidade instrumental da idade moderna e nas soluções buscadas de maneira eficaz, com total neutralidade social e 
política, visando deter o monopólio da ciência (BREZEZINSKI, 2007, p. 246 , grifos nossos).

A autora enfatiza que o professor licenciado em de Pedagogia não é formado apenas para atuar na Educação Infantil e anos iniciais do Ensino Fundamental. Isso nos preocupa, pois, em uma sociedade marcada por constantes mudanças e um curso com uma grade curricular em vigor há mais de dez anos, com quase $20 \%$ da carga horária destinada a Núcleos Livres, essas horas poderiam ser redimensionadas de maneira a contemplar as demais modalidades da educação, por exemplo, educação especial, educação de jovens e adultos, entre outras.

A discussão em torno da necessidade da inserção de conhecimentos científicos do campo educacional nos cursos de formação inicial ainda não foi equacionada. Embora haja concordância sobre a importância do professor possui conhecimentos epistemológicos e históricos da área educacional, permanece como desafio a inserção de algumas temáticas nos currículos das licenciaturas. Tal aspecto prejudica a preparação para a atuação em algumas modalidades, especialmente àquelas relacionadas às questões sociais.

Especificamente em relação à Pedagogia, sabemos que historicamente a profissão foi se constituindo com a concepção que qualquer sujeito poderia ser professor. Essa concepção ainda circunda a Educação Infantil, pois esta etapa da educação básica foi concebida inicialmente como assistencialista, ou seja, o profissional tinha como foco apenas cuidar da criança. Para Gatti (2015, p. 231):

Os professores para serem profissionais e não repentistas, ensaístas, ou quebra-galhos, necessitam ser portadores de conhecimentos sobre $\mathrm{o}$ campo educacional e sobre práticas relevantes a esse campo, e mais, necessitam ter, além de sua formação científica, uma formação humanista, de tal forma que possam torna-se professoresmestres. Pode parecer trivial, mas não é. A concepção de que qualquer um pode ser professor desde que tenha um mínimo de conhecimento sobre alguma área de conhecimento ainda é presente tanto na sociedade em geral quanto, muito especificamente, na academia. Também presente é a ideia de que não é preciso preparo anterior para dar aulas. Basta comunicar, até porque "dar aula" é algo tomado como uma atividade de menor valia.

Gatti (2015) aponta que as licenciaturas são convocadas a revolucionar suas perspectivas formativas à luz do conhecimento humanocientífico, deve-se promover a integralização de formas curriculares nas licenciaturas, interligando essas duas vertentes de conhecimento e tendo como guia o trabalho escolar.

Diante do exposto, defendemos a inclusão nos projetos pedagógicos das licenciaturas de Pedagogia de disciplinas/conteúdos que contemplem as demais modalidades de ensino, para que os futuros pedagogos estejam aptos profissionalmente e que haja sintonia com as Diretrizes Curriculares Nacionais para a Educação Básica.

O projeto pedagógico incorpora as mudanças que vêm ocorrendo na organização da educação básica, tais como a redefinição da atuação da união, estados e municípios, alterações político-pedagógicas e legais vêm se materializando, merecendo destaque a reorganização dos níveis e modalidades da educação nacional.

Diante do exposto, reafirmamos a importância política e social do currículo dos cursos de formação de professores para a atuação profissional para que tenhamos profissionais preparados e comprometidos efetivamente com uma educação pública e de qualidade. Compreendemos que apenas quatros anos de formação não são suficientes para abranger todos os desafios inerentes à profissão, porém este período deve ser o alicerce que sustentará o aluno na sua atuação profissional e cidadã, tendo autonomia para 
continuar buscando conhecimentos e lutando por uma sociedade ética, inclusiva e democrática.

\section{CONCLUSÕES}

Os problemas em torno da formação docente permanecem no contexto atual. A pouca atenção dada às licenciaturas por parte dos governos, a dispersão curricular, a separação radical entre as licenciaturas, a simbiose entre licenciaturas e bacharelados dentre outros aspectos acabam por resultar na fragmentação da formação e, consequentemente, da própria profissão.

No contexto atual, as políticas de governo responsabilizam o professor pela qualidade da educação, prática própria dos governos neoliberais que individualizam a culpa e a responsabilidade. Ao considerarmos que vários são os fatores que implicam na melhoria da qualidade da educação, podemos elencar a formação inicial, as condições de trabalho, a remuneração, o entorno escolar, dentre outros fatores que interferem diretamente na qualidade da educação.

Ao expor neste trabalho os problemas presentes no currículo de formação de professores de Pedagogia, compreendemos que é preciso refletir sobre o processo de formação para, apontar novos caminhos, também é possível afirmar que o projeto não está em consonância com os normativos legais não é uma realidade única, isolada e que mais cursos e universidades encontram-se na mesma situação.

É necessário discutir a formação de professores neste cenário de incertezas, marcado pela da precarização da profissão docente. 0 currículo dos cursos de licenciaturas tem se mostrado como uma forma de acomodação ou como um meio de resistência, pois este currículo poderá contribuir para manutenção da sociedade excludente, na qual vivemos ou resistir e contribuir para a sua transformação, visando uma sociedade mais justa equitativa.

A formação inicial deve propiciar subsídios para que o professor na sua prática possa desenvolver um ensino genuinamente público, incluindo a todos sem distinção. Compreendemos, porém, que só a formação inicial não é suficiente para todas essas questões, por isso o professor deve estar sempre em formação, visto que os desafios da profissão são constantes, o que exige que o professor seja capaz de compreender a dimensão política da sua atuação, reconhecendo-se enquanto classe e, como tal, possamos todos impedir a implementação de políticas neoliberais que como vendaval nos arrastam para um passado de retrocessos e perdas.

\section{REFERÊNCIAS}

BRASIL. Congresso Nacional. Lei no 9.394 de 20 de dezembro de 1996. Estabelece as diretrizes e bases da educação nacional. Diário Oficial da União, Brasília, DF, 23 dez. 1996. Disponível em: http://www.planalto.gov.br/Ccivil 03/leis/L9394. $\underline{\mathrm{htm}}$

BRASIL. Parecer CNE/CP n. 9, de 08 de maio de 2001. Diretrizes Curriculares nacionais para a formação de professores da Educação Básica, em nível superior, curso de licenciatura de graduação plena. Diário Oficial da União, Brasília, DF, 18 jan. $2002 . \quad$ Disponível em: http://portal.mec.gov.br/cne/arquivos/pdf/009.p df

BRASIL. Resolução CNE/CES n. 1, de 18 de fevereiro de 2002. Institui as Diretrizes Curriculares Nacionais para a Formação de Professores da Educação Básica, em nível superior, curso de licenciatura de graduação plena. Diário Oficial da União, Brasília, DF, 18 fev. $2002 . \quad$ Disponível em: http://portal.mec.gov.br/seesp/arquivos/pdf/res 1 2.pdf

BRASIL. Parecer CNE/CP n. 05/2005, de 13 de dezembro de 2005. Diretrizes Curriculares Nacionais para o Curso de Pedagogia. Diário Oficial da União, Brasília, DF, 15 mai. 2006. Disponível em: http://portal.mec.gov.br/cne/arquivos/pdf/pcp0 $\underline{5 \quad 05 . p d f}$

BRASIL. Resolução CNE/CP no 1, de 15 de maio de 2006. Institui Diretrizes Curriculares Nacionais para o curso de graduação em Pedagogia, Licenciatura. Diário Oficial da União, Brasília, DF, 16 mai. 2006. Disponível em: http://portal.mec.gov.br/cne/arquivos/pdf/rcp01 06.pdf

BRASIL. Ministério da Educação. Secretaria de Educação Básica. Secretaria de Educação Continuada, Alfabetização, Diversidade e Inclusão. Secretaria de Educação Profissional e 
Tecnológica. Conselho Nacional da Educação. Câmara Nacional de Educação Básica. Diretrizes Curriculares Nacionais Gerais da Educação Básica. Brasília: MEC, SEB, DICEI, 2013.

BRASIL. Resolução no 2, de 10 de julho de 2015. Define as Diretrizes Curriculares Nacionais para a formação inicial em nível superior (cursos de licenciatura, cursos de formação pedagógica para graduados e cursos de segunda licenciatura) e para a formação continuada. Diário Oficial da União, Brasília, DF, 02 jul. 2015. Disponível em: http://portal.mec.gov.br/index.php?option=com docman\&view=download\&alias=70431-res-cnecp-002-03072015-pdf\&category slug=agosto2017-pdf\&Itemid=30192

CURY, C. R. J. Educação básica. In: OLIVEIRA, D. A.; DUARTE, A. M. C.; VIEIRA, L. M. F. DICIONÁRIO: trabalho, profissão e condição docente. Belo Horizonte: UFMG/Faculdade de Educação, 2010. CDROM.

BRZEZINSKI, I. Formação de professores para a educação básica e o Curso de Pedagogia: a tensão entre instituído e instituinte. Revista Brasileira de Política e Administração da Educação Periódico Científico Editado pela ANPAE, Goiânia, v. 23, n. 2, p. 229-251, mai./ago. 2007.

DINIZ-PEREIRA, J. E. A construção do campo da pesquisa sobre formação de professores. Revista da FAEEBA - Educação e Contemporaneidade, Salvador, v. 22, n. 40, p. 145-154, jul./dez. 2013.

GATTI, B. A. Formação de professores: compreender e revolucionar. In: SILVA JUNIOR, C. A.; GATTI, B. A.; MIZUKAMI, M. G. N.; PAGOTTO, M. D. S.; SPAZZIANI, M. L. (Org.). Por uma revolução no campo da formação de professores. São Paulo: Editora Unesp, 2015, p. 229-243.

LIBÂNEO. J. C. Formação de professores e didática para desenvolvimento humano. Educação \& Realidade, Porto Alegre, v. 40, n. 2, p. $629-640,2015$. https://doi.org/10.1590/2175$\underline{623646132}$

LAKATOS, E. M. MARCONI, M. de A. Fundamentos de metodologia científica. 7. ed. São Paulo: Atlas, 2010.
LIMONTA, S. V. Currículo e formação de professores: um estudo e proposta curricular do curso de pedagogia da Universidade Estadual de Goiás. 2009. 332f. Tese (Doutorado em Educação) - Faculdade de Educação, Universidade Federal de Goiás, Goiânia.

MOREIRA, A. F.B. Currículo, cultura e formação de professores. Educar em revista, Curitiba, n. 17, p. 39-52, jan./jun. 2001.

MOREIRA, A. F. B.; CANDAU, V. M. Currículo, conhecimento e cultura. In: MOREIRA, A. F.; ARROYO, M. I. Indagações sobre currículo. Brasília: Departamento de Políticas de Educação Infantil e Ensino Fundamental, 2006. p. 83-111.

SALES, S. R. Diretrizes curriculares. In: OLIVEIRA, D. A.; DUARTE, A. M. C.; VIEIRA, L. M. F. Dicionário: trabalho, profissão e condição docente. Belo Horizonte: UFMG/Faculdade de Educação, 2010. CDROM.

SEVERINO, A. J. Metodologia do trabalho científico. 23. ed. São Paulo: Cortez, 2007.

UNIVERSIDADE FEDERAL DE GOIÁS. Projeto Político-Pedagógico Curso de Pedagogia. Goiânia-GO, junho de 2003. Disponível em: https://www.fe.ufg.br/p/4238-projeto-politicopedagogico>Acesso em 24 de out de 2017

Recebido para publicação em: 03/11/2017

Revisado em: 30/01/2018

Aceito em: 09/03/2018 